\title{
COVID-19 and balance in access to health care in Ethiopia
}

Dear Editor,

In a recent letter, Acharya (2020) argues that, "resource poor countries ought to focus on early detection and containment of novel corona virus at the point of entry". ${ }^{1}$ Ethiopia is a typical example of a resource poor country in Sub-Saharan Africa with a challenged health system and a fragile economy. The country has opted for a balanced approach. While it has adopted a raft of lockdown-style measures, industry and agriculture have continued to operate, and steps to mitigate the effects of the measures on the most vulnerable are being undertaken by both the government and non-governmental organizations. In addition, the health system is being geared up to meet the potential challenges. At the moment, the number of confirmed virus cases in the country is low (about 250) but increasing. ${ }^{2}$ While the bulk of the cases are in the capital city and in urban areas, the consequences are being felt in the rural hinterland.

The country's hospitals, especially in the capital, are being prepared to treat virus affected patients in case of community outbreak. However, such preparations are leading to adverse consequences for other health care needs. For instance, some public hospitals have been designated to provide services only for Covid patients and have completely stopped provision of out-patient and in-patient services for other health problems. At the country's premier teaching hospital, Addis Ababa University's, Black Lion (Tikur Anbessa) hospital, the hospital is prepared but as of now has not yet treated any patient with the virus and all suspected cases have been negative. Nonetheless, the fear of contracting the virus has led to a sharp reduction in outpatient and inpatient visits and increased foregone health care and self-medication.

While a focus on the virus is justified, as in the case of the debate over lives and livelihoods, a balance is needed. Foregone care will translate into unnecessary morbidity and mortality especially with regard to maternal and child care $(\mathrm{MCH})$ services. Conversations with health personnel at Black Lion hospital reveal that patients as well as children who suffer from respiratory diseases are foregoing care as they are concerned about being taken into Covid isolation centers. In other parts of the country, there have been sharp reductions in the use of ante-natal and post-natal care visits and an increase in non-institutional births. ${ }^{3}$

Efforts are now being made to set up telemedicine clinics and there have been calls by the health administration through the Ethiopian Broadcasting Corporation (EBC) to encourage mothers to use services along with safety assurances. It is imperative that a balance between focusing the health services on handling the virus and at the same time not ignoring other essential services is preserved. Otherwise, the hard won and spectacular reduction in maternal mortality and the sharp increase in institutional births achieved in Ethiopia in recent years will be squandered. ${ }^{4}$

\section{References}

1. Acharya KP. Resource poor countries ought to focus on early detection and containment of novel corona virus at the point of entry. Clin Epidemiol Global Health. 2020. https://doi.org/10.1016/j.cegh.2020.03.001.

2. Available https://tena.et/update?lang=en. Accessed: 4 May 2020.

3. Available https://www.voanews.com/science-health/coronavirus-outbreak/covid19-limits-force-ethiopian-mothers-give-birth-home. Accessed: 11 May 2020.

4. Rieger M, Wagner N, Mebratie AD, Alemu G, Bedi AS. The impact of the Ethiopian health extension program and health development army on maternal mortality: a synthetic control approach. Soc Sci Med. 2019;232:374-381.

Zemzem Shigute

Erasmus University Rotterdam and Addis Ababa University, Ethiopia

Anagaw Derseh Mebratie School of Public Health, Addis Ababa University, Ethiopia

Getnet Alemu

Addis Ababa University, Ethiopia

Arjun S. Bedi

Erasmus University Rotterdam, Netherlands

" Corresponding author. E-mail address: bedi@iss.nl (A.S. Bedi). 